\title{
Research and Its Concepts
}

\author{
Dr. Manish Sharma ${ }^{1}$
}

Keywords: Research, Psychology

\section{INTRODUCTION:}

The prefix 'Re' in the word 'research' according to the Concise Oxford Dictionary means 'Frequentative and Intensive'. Therefore only that category of investigation can properly be called 'Research' which

i) Attempts to verify the data obtained through the study in a variety of ways and

ii) Each verification should have exposed the data to a severe and intensive scrutiny

As such, according to me, "Research" means "a systematic, frequentative and intensive study of the data" (with a view to extend our knowledge)

The Sanskrit equivalents of the English word "Research" are as follows

i) Nirupana" i.e.

ii) Anvesana i.e.

iii) Anusandhana i.e.

iv) Vichrana i.e.

v) Marganin

vi) Jignasa
Ascertaining, determination

Searching after (some hidden causes or relation of things)

Close inspection

Reflection

Investigation

inquisitiveness

Thus "Research" should mean investigation consisting of determination and inspection of, or reflection upon, facts with a view to determine, of search, something which may satisfy the curiosity of the investigator, and as a result of the same, carry his knowledge forward. This definition is also silent on the object of research although it is comprehensive enough to include almost all the aspects of-

${ }^{1}$ Assi. Prof. Sardar Patel University, Gujarat

(C) 2015 I M Sharma; licensee IJIP. This is an Open Access Research distributed under the terms of the Creative Commons Attribution License (http://creativecommons.org/licenses/by/2.0), which permits unrestricted use, distribution, and reproduction in any Medium, provided the original work is properly cited. 
- the research method and also emphasize upon the subjective element (jignasa) which is responsible for it. However, beside jignasa, a research scholar should not only have an abundant fund of extraordinary will power and self discipline but also a fervor of a devoted youthful lower whose enthusiasm vaxes every day into fresh vigorous efforts.

However, it should be borne in mind that the knowledge so acquired should not have its validity limited only to the data under scrutiny but should have universality about it. That is to say, it should have a general applicability and relevance to a similar category of data anywhere. It should hold good or be applicants to the entire range of the same kind of phenomena.

This definition will make it clear that it is wrong to restrict the meaning of the word "Research" to laboratory work only which has for its method chiefly experimentation to manipulation of the data under controlled conditions. The restriction of the word "Research" to "laboratory investigation" only rests upon (i) the misconception of the scientific method of enquiry and (ii) the confusion of a method of scientific method. In fact any study can claim to be called scientific wherein data are subjected logical analysis regardless of the fact whether the result are obtained by experiment statistics or common sense. Even of the subject matter or data of any particular discipline does not admit of the possibility of experimentation to verify the data (i.e. geology, astronomy etc.) it cannot on that ground, and for that reason, be excluded from the preview of the scientific study, nor can such a study be prevented from being called scientific, if the data are obtained by and amenable to, a process of logical analysis which broadly consist of induction and deduction. Induction means particular to general and education mean general to particular.

Research work may broadly be divided into three categories (a) Physical Science Researches (b) Social Science Researches and (c) Literary Researches. But they all meet on the common ground of the Scientific method employed by them. In the physical sciences one does not variably begin with a clean slate. They required consultation with already written material, such as reports of other scientists, and in this respect, this type of research work takes part in the nature of researches in social sciences (such as history) and literary field. Similarly, although literary research belongs mainly to the field of creative work, the method adopted in this area of investigation is also same as that of historian who goes through a number of 
ancient texts to verify any data or fact. Literary research lies in gathering and ordering concepts and information from published and unpublished sources relevant to the study of any other. Here the degrees and extent of diligence and caution expected to be used by the scholar are the same in other good scientific research work in the field of both physical and social science. The scholar has to collect fragments of information and checks them against other information obtained from other sources and also to scrutinize the varying degrees of reliability of these sources. Every scientific research work today in any of the three fields mentioned above uses all these methods in conjunction but in different degrees.

Another type of classification seeks to divide the research work in the (i) Pure and (ii) applied researches i.e, research work undertaken solely with the purpose of extending knowledge and research taken in hand with the intention of developing practical application of results. But such a distinction is rarely a clear one. Pure research sometimes turns out to possess unforeseen practical potentialities and the applied research also sometimes yields purely theoretical results. Actually except in physical sciences, the real distinction lies in attitude and pay rather than in the method of motives behind the research work. In fact, sooner this distinction is done away with the better the recognition of the irrelevance of the idea of acquisition of knowledge for its own sake as the ideal of research work in the field of social sciences and literature will emancipate the research activity in these fields from a great many handicapping factors.

Each organized investigation requires some subjective propulsion with some hypothesis or problem in mind a researcher proceeds to collect, select, evaluate and organize the data relevant to his studies and the rest he leaves untouched. If there is no such sense of direction or purpose, i.e. if no subjective element is present in his research work, he will not be in a position to make the necessary selection and elimination from the data, and without this process no research work is possible. The slogan "Research for research sake" or research for truth's sake does not profile the subjective element so vitally necessary for any research activity.

Formerly research work was undertaken by an individual (a social) scholar who plunged deep into his studies to discover truth for its own sake. Today this concept of research is no longer valid because of the shift of emphasis from the rational to experimental of observational aspect, which presupposes corporate work. The increase in the complexities of data and the development of complicated 
techniques require sharing of labour and information to a very large extent. Today research scholars work together in great centers of research financed by government, industrial organizations, universities or foundations. Here a large number of scholars belonging to different fields, applying different norms, employing to different techniques and seeking different ends are found working together at one place, helping others and being helped by others in ones field of specification. All of them are working here for satisfying some social demand. As the research work in history has the element of contemporary in it because it is an outcome of pressures, pulls and problems weighing upon society at a particular hour, the research work in physical sciences and literary fields are also products of tension, strain and requirements of a particular hour. All research work (in any field) is an outcome of individual reaction to social needs, even though he might not be conscious of it at times. Social needs should be aimed at through the satisfaction of individual desires.

There is great truth in the maximum that individuals often serve society unknowingly and research work is no exception to these rules.

\section{REFERENCES}

Romila, Thapar- Decolonising the past, Historical writing in the time of sachin -and Beyond, Economic and Political weekly April2, 2005.

Ali Daud (ed) ,Invoking the Past, The uses of History in South New Delhi 1999.

R P Dutt- India today London 1940. 